\title{
Endoscopic biliary access after pancreaticoduodenectomy following Imanaga's procedure
}

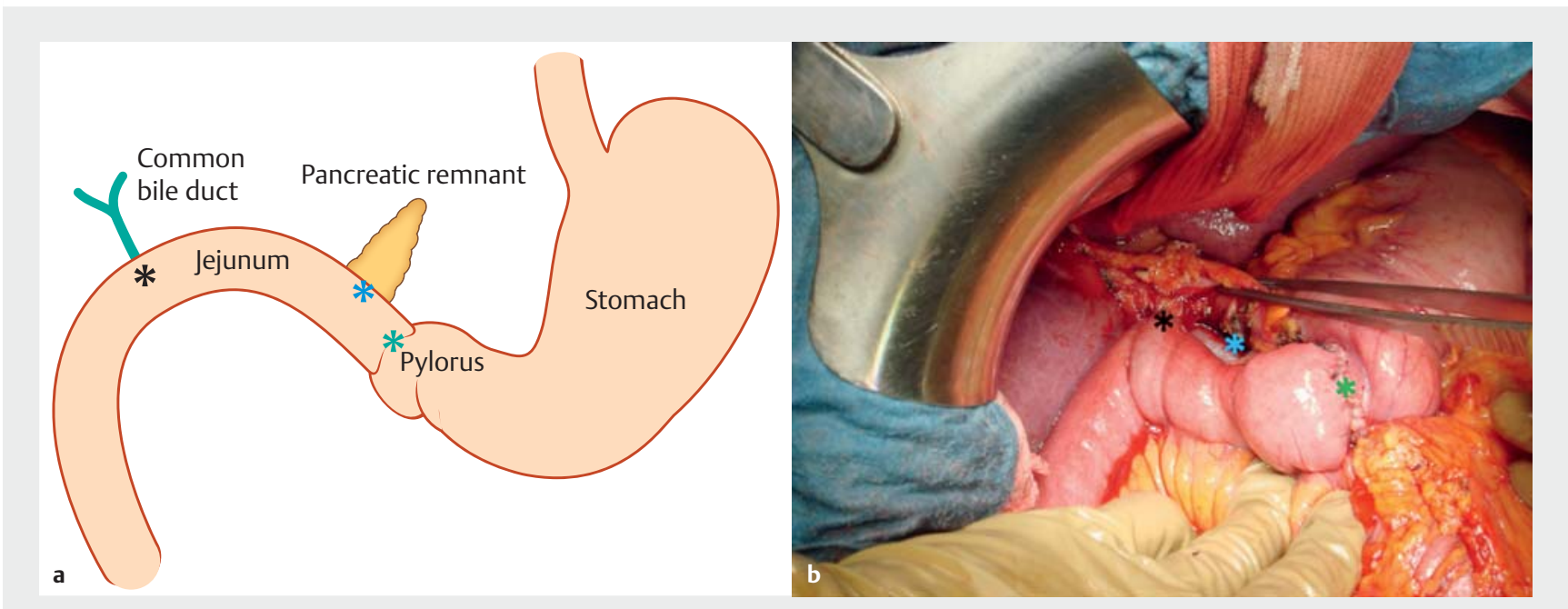

- Fig. 1 a Schematic representation of the Imanaga's montage. b Surgical view with the duodenojejunal anastomosis (green asterisk), the pancreaticojejunal anastomosis (blue asterisk), and the choledochojejunal anastomosis (black asterisk).

Endoscopic retrograde cholangiopancreatography $(\mathrm{ERCP})$ is the technique of choice to drain the main biliary duct with a high degree of technical success [1]. However, in the case of a pancreaticoduodenectomy, endoscopic biliary access can be challenging. Imanaga's procedure is a pylorus-preserving pancreaticoduodenectomy procedure with the duodenojejunal, pancreaticojejunal, and hepaticojejunal anastomosis reconstructed in that order on the jejunal limb ( Fig. 1) [2, 3]. This procedure is thought to allow easier endoscopic access to the hepaticojejunal anastomosis [4].

Here we report two cases of endoscopic biliary access after Imanaga's procedure. ( $\triangleright$ Video 1 ). The first case is a 70-yearold man who underwent Imanaga's procedure 4 months before for a duodenal lesion that could not be resected endoscopically. He subsequently had cholestasis with a stenosis of the biliary anastomosis. The anastomosis was hard to find with a duodenoscope, but thanks to immersion, the anastomosis was retrieved and cannulated with deployment of a

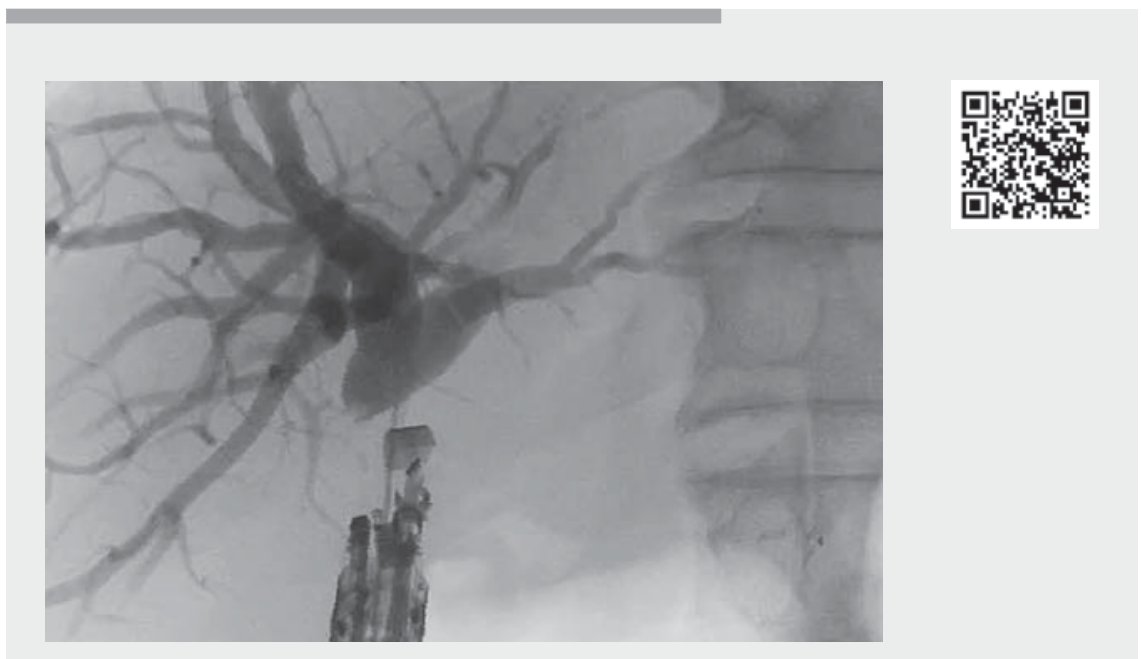

$\nabla$ Video 1 Endoscopic biliary access after pancreaticoduodenectomy following Imanaga's procedure.

self-expandable metal stent to calibrate the anastomosis ( $\mathbf{F i g . 2}$ ).

The second case is a 70-year-old man who underwent Imanaga's procedure 1 month before for an intraductal papillary mucinous neoplasm. A stenosis of the biliary anastomosis occurred with cholestasis and one episode of cholangitis. Endoscopic management of the stenosis was decided. Despite intensive searching, the biliary anastomosis was not found. An echoendoscope was used to 


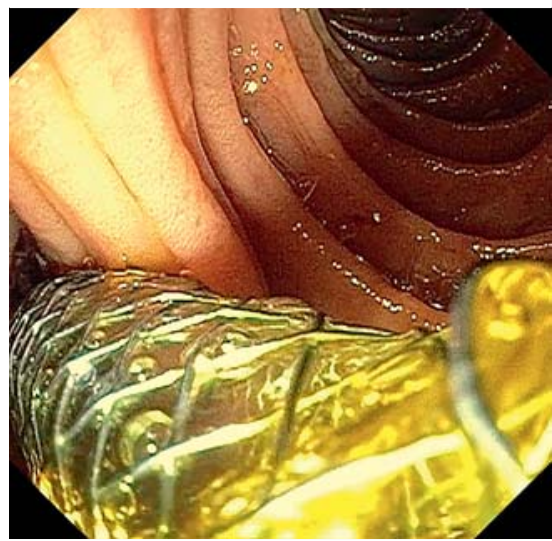

- Fig. 2 Self-expandable metal stent deployed at the choledochojejunal anastomosis.

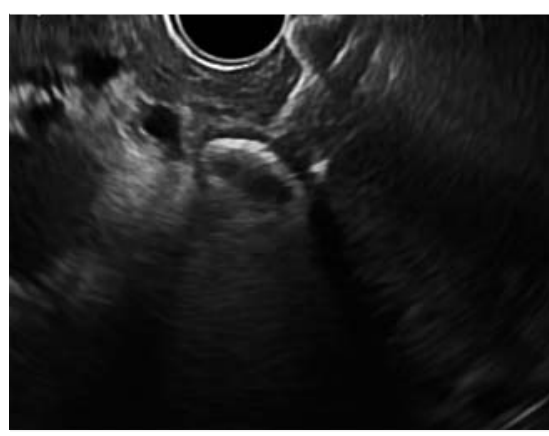

- Fig.3 Deployment of a lumen-apposing metal stent at the choledochojejunal anastomosis.

visualize the common bile duct with a dilation of $7 \mathrm{~mm}$ and a clear stop. With a 19G needle, the biliary duct was punctured and opacified, and a guidewire was then positioned. To recalibrate the biliary anastomosis, a lumen-apposing metal stent was deployed, allowing satisfying biliary drainage ( $\triangleright$ Fig.3). Neither patient experienced any adverse event, and their cholestasis improved in the following days.
This e-video illustrates two successful endoscopic biliary accesses in patients with a history of pylorus-preserving pancreaticoduodenectomy following Imanaga's procedure without the need of double-balloon endoscopy.

Endoscopy_UCTN_Code_TTT_1AR_2AZ

\section{Competing interests}

The authors declare that they have no conflict of interest.

\section{The authors}

Thomas Lambin ${ }^{1,2}$, Jérôme Rivory ${ }^{1}$, Mustapha Adham $^{3}$, Florian Rostain ${ }^{1}$, Thierry Ponchon ${ }^{1}$, Pierre Lafeuille ${ }^{1}$, Mathieu Pioche ${ }^{1,2}$

1 Gastroenterology and Endoscopy Unit, Pavillon L, Edouard Herriot Hospital, Lyon, France

2 Inserm U1032, Labtau, Lyon, France

3 Digestive Surgery Unit, Edouard Herriot Hospital, Lyon, France

\section{Corresponding author}

\section{Thomas Lambin, MD}

Endoscopy Unit, Digestive Disease Department, Pavillon L, Edouard Herriot Hospital, 69437 Lyon Cedex, France thomaslambin@hotmail.fr

\section{References}

[1] Balik E, Eren T, Keskin M et al. Parameters that may be used for predicting failure during endoscopic retrograde cholangiopancreatography. J Oncol 2013; 2013: 201681

[2] Imanaga $\mathrm{H}$. A new method of pancreaticoduodenectomy designed to preserve liver and pancreatic function. Surgery 1960; 47 : 577-586
[3] Kimura Y, Yasukawa D, Aisu Y et al. Imanaga's first method for reconstruction with preservation of mesojejunal autonomic nerves during pylorus-preserving pancreatoduodenectomy. Am J Case Rep 2018; 19 : 608-613

[4] Krige JE, Nicol AJ, Navsaria PH. Emergency pancreatoduodenectomy for complex injuries of the pancreas and duodenum. HPB 2014; 16: 1043-1049

Bibliography

Endoscopy 2022; 54: E360-E361

DOI 10.1055/a-1540-6827

ISSN 0013-726X

published online 9.8.2021

(c) 2021. Thieme. All rights reserved.

Georg Thieme Verlag KG, Rüdigerstraße 14,

70469 Stuttgart, Germany

\section{ENDOSCOPY E-VIDEOS}

https://eref.thieme.de/e-videos

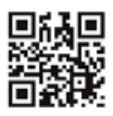

Endoscopy E-Videos is an open access online section, reporting on interesting cases and new techniques in gastroenterological endoscopy. All papers include a high quality video and all contributions are freely accessible online. Processing charges apply (currently EUR 375), discounts and wavers acc. to HINARI are available.

This section has its own submission website at https://mc.manuscriptcentral.com/e-videos 